\title{
18
}

\section{The Fourth Conception of Being}

Any doctrine concerning fundamental questions is likely to meet with two different sorts of objections. The objections of the first sort maintain that the theory in question is too abstruse and obscure to be comprehended. The objections of the second sort point out that this same theory is too simple to be true. Every teacher of philosophy becomes accustomed not only to hear both kinds of objections from his more thoughtful pupils, but to urge them, for himself, upon his own notice. No one, in fact, is a philosopher, who has not first profoundly doubted his own system. And it is in presence of objections that philosophical theses best show their merits, if they have merits.

Upon the present occasion I have more fully to develope the conception of Being to which we were led at the close of the last discussion. While I shall do so, in the first place, independently, I shall come before I am done into intimate connection with some of the principal objections that may be urged against our theses regarding the definition of what it is to be. For the objections will help us to make clearer our position.

I

But let us first restate our thesis as to the nature of Being. There is an ancient doctrine that whatever is, is ultimately something Indi-

[Reprinted from $W I, \mathrm{r}: 345-82$. 
vidual. Realism early came to that view; and only Critical Rationalism has ever explicitly maintained that the ultimate realities are universals, namely, valid possibilities of experience, or mere truths as such. Now at the close of the last lecture, after analyzing the whole basis of Critical Rationalism, the entire conception of the Real as merely valid, we reinstated the Individual as the only ultimate form of Being. In so far we returned to a view that, in the history of thought, Realism already asserted. But we gave a new reason of our own for this view. Our reason was that the very defect of our finite ideas which sends us seeking for Being lies in the fact that whether we long for practical satisfaction, or think of purely theoretical problems, we, as we now are, are always seeking another object than what is yet present to our ideas. Now any ultimate reality, for us while as finite thinkers we seek it, is always such another fact. Yet this other object is always an object for our thought only in so far as our thought already means it, defines it, and wills it to be our object. But what is for us this other? In its essence it is already defined even before we undertake to know it. For this other is precisely the fulfilment of our purpose, the satisfaction of the will now imperfectly embodied in our ideas, the completion of what we already partially possess in our finite insight. This completion is for us another, solely because our ideas, in their present momentary forms, come to us as general ideas,ideas of what is now merely a kind of relative fulfilment and not an entire fulfilment. Other fulfilment of the same general kind is needed before we can face the whole Being that we seek. This kind of fulfilment we want to bring, however, to some integral expression, to its own finality, to its completeness as a whole fact. And this want of ours, so I asserted, not only sets us looking for Being, but gives us our only ground and means for defining Being.

Being itself we should directly face in our own experience only in case we experienced finality, i.e. full expression of what our finite ideas both mean and seek. Such expression, however, would be given to us in the form of a life that neither sought nor permitted another to take its own place as the expression of its own purpose. Where no other was yet to be sought, there alone would our ideas define no other, no Being, of the type in question, lying yet beyond themselves, in the direction of their own type of fulfilment. The other would be found, and so would be present. And there alone should we consequently stand in the presence of what is real. Con- 
versely, whoever grasps only the nature of a general concept, whoever merely thinks of light or colors, or gravitation, or of man, whoever lacks, longs, or in any way seeks another, has not in his experience the full expression of his own meaning. Hence it is that he has to seek his object elsewhere. And so he has not yet faced any ultimate Being. He has upon his hands mere fragments, mere aspects of Being. Thus an entire instance of Being must be precisely that which permits your ideas to seek no other than what is present. Such a being is an Individual. Only, for our present conception of Being, an individual being is not a fact independent of any experience, nor yet a merely valid truth, nor yet a merely immediate datum that quenches ideas. For all these alternatives we have already faced and rejected. On the contrary an individual being is a Life of Experience fulfilling Ideas, in an absolutely final form. And this we said is the essential nature of Being. The essence of the Real is to be Individual, or to permit no other of its own kind, and this character it possesses only as the unique fulfilment of purpose.

Or, once more, as Mysticism asserted, so we too assert of your world, That art thou. Only the Self which is your world is your completely integrated Self, the totality of the life that at this instant you fragmentarily grasp. Your present defect is a matter of the mere form of your consciousness at this instant. Were your eyes at this instant open to your own meaning, your life as a whole would be spread before you as a single and unique life, for which no other could be substituted without a less determinate expression of just your individual will. Now this complete life of yours, is. Only such completion can be. Being can possess no other nature than this. And this, in outline, is our Fourth Conception of Being.

\section{II}

Now I cannot myself conceive any one lightly accepting such a definition as this,-a definition so paradoxical in seeming, so remote from the limits which common sense usually sets to speculation, and so opposed to many dignified historical traditions; and indeed I wish nobody to accept it lightly. The whole matter is one for the closest scrutiny. The only ground for this definition of Being lies in the fact that every other conception of reality proves, upon analysis, to be self-contradictory, precisely in so far as it does not in essence agree with this one; while every effort directly to deny 
the truth of this conception proves, upon analysis, to involve the covert affirmation of this very conception itself. Upon these assertions of the absolute logical necessity of our conception of Being, our whole case in this argument rests. And in order to make this fact clearer, I must briefly review the former argument.

Our argument in the last lecture was based upon the consideration that Being has, at all events, to be that object which makes ideas true or false. The more special features of our analysis of the relation of idea and object were as follows:-

An idea and its real object, in case the idea has any real object, must indeed plainly possess some characters in common. There must thus be general, or abstractly universal, features, belonging to them both. Upon that point all theories of Being to some extent agree. Even the Mystic, at the moment when he calls all ideas vain, identifies your true Self-yes, the very Self that now has your poor ideas-with the Absolute, and says of your object, viz. of the true Being, "That art thou." Even the Realist, despite the independence of his Beings, holds that the ideas either truly represent the nature of these beings, or else, at all events, have in common with even the unknowable object some features whereby the object embodies in reality the same fact which the idea aims to express when it seeks for the reality. The failure of Realism we found to be due to the logical impossibility of reconciling the independent Being of the object of our ideas with this inevitably assumed sameness of nature, which must be possessed, in however slight a measure, by both the knowing idea and the object that it knows. In the world of the Third Conception of Being, that of Validity, the ideas express with more or less precision, and in their own way, precisely that truth which is to be valid beyond them. And, in fact, as we just saw, the most general conditions which determine for us the problem of Being, demand that the purpose which every idea has in seeking its Other, must have some element in common with that which fulfils this very purpose.

Idea and Reality must, then, possess elements that are common to both of them. On the other hand, as we saw, this mere community is wholly inadequate to the tasks of defining what makes the object belong, as object, to a given idea. For, if you view any idea and its supposed object, merely as one might be imagined viewing them from without, it is wholly impossible to determine what degree of correspondence between them is required either to make 
the reality that precise object sought by the idea, or to render the idea the true representative of the object to which it is said to refer. A true idea, as Spinoza said, must indeed resemble its ideate. But on the other hand, a mere resemblance of idea and ideate is not enough. Nor does the absence of any specific degree of resemblance necessarily involve an error. It is intended resemblance which counts in estimating the truth of ideas. If in fact you suppose, as an ideal case, two human beings, say twins, absolutely to resemble each other, not only in body, but in experience and in thought, so that every idea which one of these beings at any moment had was precisely duplicated by a thought which at the same instant, and in the same fashion, arose in the other being's life,-if, I say, you suppose this perfect resemblance in the twin minds, you could still, without inconsistency, suppose these twins separated from infancy, living apart, although of course under perfectly similar physical conditions, and in our human sense what we men call absolute strangers to each other, so that neither of them, viewed merely as this human being, ever consciously thought of the other, or conceived of the other's existence. In that case, the mere resemblance would not so far constitute the one of these twin minds the object of which the other mind thought, or the being concerning whom the ideas of the other were true.

The resemblance of idea and object, viewed as a mere fact for an external observer, is, therefore, never by itself enough to constitute the truth of the idea. Nor is the absence of any externally predetermined resemblances, such as you from without may choose to demand of the idea, enough to constitute any specific sort of error. Moreover, when you merely assert that in the world of Being there is to be found an object which resembles your idea, you have so far only mentioned two beings, namely, your idea and its object, and have asserted their resemblance. But you have not yet in the least defined wherein the Being of either of these objects consists. This, then, is the outcome so long as you view idea and object as sundered facts agreeing or disagreeing with each other. Neither truth nor Being is thus to be defined. The result so far is conclusive as against the adequacy, not only of Realism, and of Mysticism, but also, as we saw, of even the Third Conception of Being.

For if one asserts, as his account of the nature of Being, that certain ideas of possibilities of experience are valid, he is so far left 
with a world of objects upon his hands whose only character, so far as he yet defines the Being of these objects, is that these objects are in agreement with his ideas. Such a definition of Being constituted the whole outcome of the Third Conception. The mathematician's ideas, as present to himself, take the form of observed symbols and diagrams. These, so far as they are observed, are contents of experience fulfilling purpose. They so far conform to our definition of what constitutes an idea, for they have internal meaning. But the existent objects concerning which the mathematician endeavors to teach us, are, by hypothesis, not the symbols, and not the diagrams, but valid truths to which these diagrams and symbols-these mathematician's ideas-correspond. The existences of the mathematician's realm are other than his mere finite ideas. Now that such objects have their place in reality, I myself thoroughly believe. But I point out that their reality, the true Being of these objects, is in no wise defined when you merely speak of the ideas as nothing but valid, because the assertion of validity is so far merely the assertion of a correspondence between a presupposed idea and its assumed object, without any account as yet either of the object, or of the truth of the idea. And bare correspondence, the mere possession of common characters in idea and in object not only fails to define, but, as we now see, can never lead us to define, the Being of either idea or object, and in no sense shows or explains to us the relation whereby the idea means, selects, and is in just this way true of just this one object.

The relation of correspondence between idea and object is, therefore, wholly subordinate to another and far deeper relation; and so to say, "My idea has reference to a real Being," is to say, "My idea imperfectly expresses, in my present consciousness, an intention, a meaning, a purpose; and just this specific meaning is carried out, is fulfilled, is expressed, by my object." For correspondence to its object, and intentional selection of both the object and the sort of correspondence, constitute the two possible relations of idea and object. If the bare correspondence determines neither Being nor truth, the intention must determine both Being and truth. In other words, the Being to which any idea refers is simply the will of the idea more determinately, and also more completely, expressed. Once admit this definition of the nature of Being, and you will accomplish the end which all the various prior definitions of Being actually sought. 
For, first, with the realist, you will now assert that the object is not only Other than the finite idea, but is something that is authoritative over against the finite idea. The realist gave an abstract expression to this authority of the object when he said that the object is independent of the idea. The abstraction was false; but it was already a suggestion of the true meaning. The finite idea does seek its own Other. It consciously means this Other. And it can seek only what it consciously means to seek. But it consciously means to seek precisely that determination of its own will to singleness and finality of expression which shall leave it no Other yet beyond, and still to seek. To its own plan, to its own not here fully determined purpose, the idea at this instant must needs submit. Its very present conscious will is its submission. Yet the idea submits to no external meaning that is not the development of its own internal meaning. Moreover, the finite idea is a merely general idea. But what it means, its object, is an Individual. So you will all agree with the realist that whether or no the idea just now embodies its own object of search as nearly with present truth as the narrow limits of our consciousness permit, it must still seek other fulfilment than is now present, and must submissively accept this fulfilment as its own authoritative truth. But you will reject the realistic isolation of the idea from the object, and of the object from the idea.

If one atempts in some way to modify his Realism by declaring the object not wholly, but only partially, independent of the ideas which refer to it, still such a modified realist would only the more have to face, as we ourselves have been trying to face, the problem as to how the idea and its object are positively related. And if idea and object are left in the end in any way as two separate existent facts, isolated from each other, then one can find no further relation between the isolated idea and object except the relation of greater or less correspondence, and by this relation of mere external correspondence, taken alone, one would be able to define neither the Being of any object, nor the truth of any idea. Or, in other words, a world where ideas and objects merely correspond, as isolated facts, and where no other and deeper relation links knowledge and Being, is a world where there is so far neither any knowledge nor any Being at all.

But secondly, if you accept our Fourth Conception, you will also agree with Mysticism in so far as, identifying Being with ful- 
filment of purpose, the mystic says, of the object of any of your ideas: That art thou. For the mystic means this assertion not of the imperfect self of the merely finite idea. He does not mean that this passing thrill of longing is already fully identical with the Other that this very longing seeks. For the mystic, as for the realist, Being is indeed something Other than our mere search for Being. The mystical identification of the world and the Self is meant to be true of the completed, of the fulfilled and final, or Absolute Self. Now, starting with any idea, we shall henceforth say to this idea, regarding its own object, precisely what the mystic says of the Self and the World: That art thou. Namely, the object is for us simply the completely embodied will of the idea. It is nothing else. But we shall henceforth differ from the mystic precisely at the point where the mystic takes refuge in mere negations. We, too, of course, shall also confess our finite ignorance. But the Neti, Neti of Yâjnavalkya, the nescio, nescio of the mediæval mystic, will express for us, not the essential nature of true Being, as the mystic declared, but merely the present inadequacy of your passing idea to its own present and conscious purpose,-a purpose known precisely so far as it is embodied at this instant. We shall say if we follow to its conclusion this our Fourth Conception, "We know in part, and we prophesy in part; but when the object meant, namely, precisely when that which is perfect is truly said to be, it fulfils, and in so far by supplementing but not otherwise, it takes away that which is in part." Our final object, the urbs Sion unica, mansio mystica, is for us, as for the mystic, the unique Being wherein this our finite will is fulfilled. But this one object meant, this fulfilment of our will, is not merely "founded in heaven." Its will is done on earth, not yet in this temporal instant wholly as it is in heaven, but is still really done, in these ideas that already consciously attain a fragment of their own meaning. They are ideas precisely because they do this. The sadness of the mystical longing is now for us lighted by glimpses of the genuine and eternally present truth of the one real world. It is not merely in the mystic trance, but in every rational idea, in so far as it is already a partially embodied purpose, that we now shall in our own way and measure come upon that which is, and catch the deep pulsations of the world. Our instant is not yet the whole of eternity; but the eternal light, the lux eterna, shineth in our every reasonable moment, and lighteth every idea that cometh into the world. 
And, thirdly, if you follow our Fourth Conception, you will now agree with the critical rationalist when he asserts that Being essentially involves what gives the validity to ideas. But you will have discovered what conditions are necessary to constitute validity. The valid finite idea is first, for whoever possess it, an observed and empirical fulfilment of purpose. But this fulfilment is also observed in this instant as something incomplete. Therefore it is that a finite idea seeks beyond itself for its own validity. And it is perfectly true to say that if the idea is valid, certain further experience of the fulfilment of the idea is possible. Leave this further experience, however, as something merely possible, and your definition of Being would so far remain fast bound in its own fatal circle. Is the idea valid or not? If it is valid, then, by hypothesis, further experience that would confirm the idea is possible. This further experience, like any object existent in the mathematician's realm, is both known to be something Other than the idea that refers to it, and is also viewed as a fact precisely corresponding to what the idea means to define. Now so long as you call this Other, this possible experience, merely such a bare possibility, you define, as we have said, only those characters of this object which the object has in common with your merely present idea of the object. The object is so far defined as an experience, and as having this or that type or form. That is what you say when you talk of any being in Kant's realm of Mögliche Erfabrung, or of any mathematical fact. All that is thus defined about the object is its mere what, the characters that it shares with your present ideas and experiences at the moment when you define it. What therefore you have not thus defined is precisely the Being of the object as Other than the very finite idea which is to regard it as an Other. If you have once observed this defect of any assertion of a bare possibility of experience, you will have seen why the mere definition of universal types can never reach the expression of the whole nature of real Beings, and why, for that very reason, the realm of Validity is nothing unless it is more than merely valid, nothing too unless it takes an individual form as an unique fulfilment of purpose in a completed life.

But all the three former conceptions are now to be brought into synthesis in this Fourth Conception. What is, is authoritative over against finite ideas, as Realism asserted, is one with the true meaning of the idea, as Mysticism insisted, and is valid as Critical Ration- 
alism demanded. What is, presents the fulfilment of the whole purpose of the very idea that now seeks this Being. And when I announce this as our Fourth Conception of Being, I do not mean to be understood as asserting a mere validity, but as reporting facts. I do not any longer merely say, as we said at the outset of our discussion, Being is that which, if present, would end your finite search, would answer your doubts, would fulfil your purpose. All that was the language of validity. It was a mere preliminary. Since validity has no meaning unless its general types of truth take on individual form, and unless the what turns into the that, I now say, without any reserve, What is does in itself fulfil your meaning, does express, in the completest logically possible measure, the accomplishment and embodiment of the very will now fragmentarily embodied in your finite ideas. And I say, that this embodiment means in itself precisely what your present embodiment of purpose in your rational experience means, just in so far as your purposes are not mere fragments, but are also, even in their transiency, results known as, relatively speaking, won, as possessed, as accomplished. The accomplishment of your purpose now means that your experience is viewed by you as the present and conscious expression of a plan. Well, what is, precisely in so far as it is, is in the same way a whole experience finally expressing and consciously fulfilling a plan. And the Being of the real object of which you now think means a life that expresses the fulfilment of just your present plan, in the greatest measure in which your plan itself is logically capable of fulfilment.

Into this categorical assertion of a concrete experience embodying a plan, our whole series of hypothetically valid assertions of the realm of Critical Rationalism have now resolved themselves. A will concretely embodied in a life,-and these meanings identical with the very purposes that our poor fleeting finite ideas are even now so fragmentarily seeking, amidst all their flickerings and their conflicts, to express,-this, I say, is the reality. This alone is. All else is either shadow, or else is partial embodiment, i.e. is a striving after that ideal which needs for its own expression this very striving. This alone is real,-this complete life of divine fulfilment of whatever finite ideas seek. It is because the finite idea essentially seeks its Other, so long as it remains indeterminate, that the quest can be attained only when the will of the idea is so embodied that no other embodiment is to be sought. It is because no quest can 
be defined as a quest without defining valid possible experiences such as would fulfil or defeat this quest, and it is because no such valid possible experiences can be defined without presupposing that something more than mere validity is real,--it is because of all these considerations that we define the fulfilment of the finite quests embodied in our present and partial ideas as the essential nature of Being.

\section{III}

So far, then, we have restated and developed our Fourth Conception of Being as the only one capable of defining how an idea can correspond to an object which is other than the idea, but which is still the very object consciously meant by the idea.

But now are there not perfectly natural objections to this conception? There are. They appear in both the before mentioned forms,-as assertions that our conception is too complex and abstruse for the plain-minded man, and as assertions that our definition is too simple for the complexities of the actual universe. Both sorts of objections, however, will prove to be welcome aids to the very comprehension of our conception of Being itself. Let me here begin with a very familiar form that an empirical objection to our theory may take.

"After all," one may say, "you in vain endeavor, through your analysis of this or that conception of Being, to escape the conclusion of enlightened common sense that experience, and experience alone, determines what is and what is not. The whole question as to Being comes in the end to this: A man can frame ideas as he will, and as you say, ideas are indeed wilful enough constructions of merely conceived possibilities. But the question about Being always is, Does experience confirm the ideas? That idea expresses Being which is found to be confirmed by experience. Upon this view of Being all sane science is founded. But this view excludes all a priori constructions, and all efforts to pierce the mysteries of the Absolute. Constructions of ideas about possibilities of experience are often allowable enough in science, as mere hypotheses, or as assertions about what is probable. But the test is the concrete, present, immediate experience of this or that observer. What has been seen, felt, or otherwise empirically encountered by some body, is in so far real. Nothing else is for us men knowable about the constitution 
of Being. Now when you talk about Being as a final fulfilment of ideas, and of human experience as a mere fragment of such a final fulfilment, you transcend human experience. Your view is too abstruse and artificial for plain men. We no longer seek, in these days, for any absolute or final Being. We believe what we find. Nothing final is experienced by men. The realm of the empirical is always, as you say, fragmentary. But then this is the only realm known to men. This alone is for us real. Ideas furnish us the what. Concrete experience alone can supply the that. I conceive in idea a horse. In experience I thereupon see, touch, drive, or buy and sell horses. Other men do the same. Hence horses are real. But I conceive of a fairy. My idea is perhaps vivid. But still I never see fairies, and I find that none but children and ignorant people fancy that they have seen fairies. So fairies remain unobserved, and so far appear to be unreal. The same rule holds in science. Neptune was first ideally conceived, but this idea was verified by astronomical observation; for the predicted planet was later observed. So Neptune is a reality. But the heavenly spheres of an older astronomy proved to be mere ideas, since advancing experience proved to be inconsistent with the ideas in question. So in science and in life, it is experience which decides that any supposed Being, whose what an idea defines, exists. Away, then, with your hope of finality. Experience is fragmentary, growing, and finite. And Being is only known through experience."

So far the objector. I reply, in a way already indicated at the last lecture. I myself doubt not in the least that the realm of experience is, and is decisive of truth. I doubt not this, simply because our Fourth Conception declares that what is real is an experience presenting the fulfilment of the whole purpose of ideas.

Nur in der Erfabrung ist Wabrbeit, said Kant. I not only accept this thesis, but insist upon it. I know of no truth that is not an empirical truth, whatever further character it also possesses. An idea, according to our original definition, is already a fragment of experience although partially fulfilling a purpose. The fulfilment of an idea could not possibly take any form that was not also empirical. Neither God nor man faces any fact that has not about it something of the immediacy of a sense datum. That is for my conception a logical necessity. For what finite ideas seek is expression, embodiment, life, presence. Experience then is real. Ay, but what experience? And above all, in what sense is experience real? What kind of Being has experience? This question must be an- 
swered by any one who glibly asserts that experience is. Now it seems strange to find that while many a man laughs to hear how some of the earlier scholastics supposed that not dogs and lions and men, but the canine nature, and leoninity in general, and humanity in the abstract are real,--still this same man will appeal to an ideal authority called Experience in general,--a mere universal idea so far,-as decisive of what is real, or as itself the reality. As a fact, only individual experience is real, be that the experience of man or God. And whoever asserts: "The reality is experience," has precisely those alternatives to face about the sense in which experience is real which have been discussed in the foregoing general account of the problem of Being.

There are in the world the experiences of men. Granted. But are these experiences facts whose Being is wholly independent of the ideas whereby we now assert that these experiences are real? If we assert this, then, our empiricism becomes simply one form of Realism. It now defines the what of our world as experience; but the that it defines, not at all merely in empirical terms, but rather in realistic terms, namely as a form of Being independent of our ideas, in so far as these ideas refer to the reality of this experience. A realistic empiricist, therefore, if you look closer, explicitly transcends the very finite experience that he declares to be the only test of truth.

For consider: Suppose that you say that the experience of mankind is a real fact, and is what it is, whatever the metaphysical dreamers say about it. Now as a finite being, confined to this instant, you do not experience my experience, nor in the same finite sense do I now and here experience your experience. If you assert that my experience is real, you in fact mean to transcend what your present finite experience presents to you. And neither your present fragment of experience can be directly used to verify the fact that my experience exists, nor can my fragment of momentary experience itself be used to verify the fact that you are thinking of me at all, or are referring to me, or are even meaning to assert my existence. And, in the same way, it is not a present fact of any man's momentary finite experience that the body of fact called the combined experience of humanity, or of science, or of any group of men, great or small, exists. Whoever asserts, then, that human experience exists, as a body consisting of the many experiences of various human observers, asserts what no finite human observer 
ever has, at any moment, experienced. For I insist, no man ever yet at any instant himself observed that mankind as a body, or that any man but himself, was observing facts.

Yet more, no man, at any one of our temporal human instants, ever then and there empirically verifies the existence even of his own past experiences. For, by definition, his past experiences are over, and are irrevocably no longer present, at any present empirical moment. No man, then, has ever observed the empirical fact that he himself has in the past observed facts, or has acquired by experience this which he now views as his own personally possessed body and outcome of experience.

Therefore, let no one who says, in a realistic sense, "Human experience, the experience of many men, exists," venture to add that he himself, or that any other man has, merely as man, empirically verified this assertion. It is false, then, to say that for such an assertion ideas furnish the what, and our human experience itself, in the form in which any man gets that experience, ever verifies the that. The assertion that a body of human experience exists, gets its that from some source not to be found in any one man's experience at any time. Our realistic empiricist is, therefore, so far precisely like other realists. He transcends every man's personal experience. $\mathrm{He}$ asserts the existence of independent Beings. He transcends all that any man ever has directly verified, or, as mere man, will at any instant ever verify. $\mathrm{He}$ is as transcendently metaphysical in his thesis as a Leibnitz or as a Herbart ever was in talking of Monads or of Reals. He can be decisively judged, however, only by the consistency of his ontological predicate. And we already know, in so far as he is a thoroughgoing realist, his fate.

For human experience, in so far as it is existent apart from our ideas which refer to it, is either something consciously meant by these ideas, or it is something not meant by them. If it is meant by them, it is either their whole real fulfilment in the form defined by our Fourth Conception; or else it is a part of just such a real final fulfilment. But, on the other hand, if it is something wholly independent in its existence of whether our private and momentary ideas refer to it or not; in other words, if it is a realm of facts whose type of Being is the realistic type, then in vain do you call it experience. Like any realistic Being, it is one whose existence cannot be referred to at all without the inconsistencies before observed. And in the end, like any other realistic Being, it is nothing at all. 
Our empiricist may then take his choice. He is with us, or against us. If he is the latter, we have already dealt with him. For just so, if the experience to which our empiricist refers is the realm of the valid possibilities of experience, we already know its meaning and outcome. Conceive the realm of possible experience consistently, and it becomes the realm of our own conception of Being. But if one means only the sort of pure experience, the bare immediacy, to which the mystic referred, that sort of experience, as we found, is again explicitly nothing at all.

But if this empirical realm in question is the genuine realm of experience to which our ideas refer when, talking of experience with rational definiteness, we mean to see clearly, to observe closely, to know richly, and to live wisely, this is indeed an empirical world, and it is real. But it is real in the sense of our Fourth Conception. It is a life expressing in fulness what every transient moment of human consciousness fragmentarily embodies, and ideally seeks.

And as to finality, what constitution shall that realm of actual experience possess at all unless this constitution, in its wholeness, is indeed final, and final precisely in the sense of our Fourth Conception? For finality means, for us, the individual constitution of the realm of fact, interpreted in the only possible consistent way. You say, "Experience is." If you are an empiricist you also say, "All that is, is, in at least one aspect, experienced fact." Now, so far, all that is precisely what our Fourth Conception says. So far we agree with any empiricist. But if you reject our Fourth Conception, you then add, "This experience which is, is, even when taken in its totality, a fragmentary experience,- a mere collection of whatever happens to be;-and this world of experience possesses no finality." But do you mean hereby that of two contradictory propositions made about the existence of a supposed individual fact in this whole realm of the real experience, both or neither may now be true? Do you mean that if I say: "There is life after death," or, "There was the siege of Troy," or, "There is the observable planet Neptune," or, "There is happiness in yonder child's heart as he sings," I can thus assert a proposition that is neither true nor false, or that is both true and false at once, and in the same sense? If this were what you asserted, the assertion would indeed mean nothing. But otherwise, if the world of experience, as a real world, has even now, while we speak, an actual constitution, then any definite proposition about the world is either true or false when it is made. But if so, my proposition with a definite internal meaning 
involves ideas that, when the proposition is made, consciously mean to refer to the existent facts of that world of real experience. But such reference to objects does not consist, as we have now sufficiently seen, in mere correspondence between idea and object. The only reference that can constitute the meaning of an idea is one which involves the complete expression of the will of the idea. But if every issue which ideas can join, with regard to the constitution of the empirical world, if every contradictory opposition which the ideas can express, has its correspondent decision, yes or no, in the facts of the truly real empirical world, then the fulfilment of the ideas about experience in the facts of experience to which they refer, is once for all a wholly determinate fulfilment. And in this case, whatever constitution the world of experience in its entirety possesses, is as such an individual and final constitution.

And so, we say, the empirical world is a whole, a life fulfilling the purposes of our ideas. It is that or it is nothing. You labor in vain. The net of truth enmeshes your doubts.

"And yet," as you may now interpose, "we have but just seen that no man experiences, for himself, at any moment, this final constitution of our realm of experience." Of course no man experiences that constitution. Now we see through a glass darkly. It is not yet revealed what we shall be. It is not yet known to us what our own whole experience itself in its details contains. But we know that it is. And we observe the constitution of that realm. It is through and through a constitution that answers our questions, embodies our meanings, integrates our purposes. It is then in essence a realm of fact fulfilling purpose, of life embodying idea, of meaning won by means of the experience of its own content. The now present but passing form of our human consciousness is fragmentary. We wait, wonder, pass from fact to fact, from fragment to fragment. What a study of the concept of Being reveals to us is precisely that the whole has a meaning, and is real only as a Meaning Embodied.

\section{IV}

"But," our objector next retorts, "your view is still too abstruse for a plain man,-for how can you thus dare to transcend the limits of human consciousness? It is true that when a man thinks, he just then consciously aims only at a meaning which is present to himself at the instant. But you talk now about the constitution of a realm of Being that is to lie beyond the limits of any merely human experience. 
For you admit that no man has yet seen at any one instant this which you call the whole of his meaning empirically expressed. Now, how can you have any assurance as to such a realm of transcendent and superhuman finality of experience? Perhaps there is experience beyond our own, perhaps not. At all events, any man actually knows only his own contents of experience, and with more or less probability he guesses at the existence of other contents than his own in other men. But nobody can assert, with real or positive assurance, any Being that transcends his own present experience. Yet you talk of final Being, and of its constitution. Perhaps there is no final Being. Perhaps there is only the present fragment of empirical life. Even my own past and future, as you say, are not present to me. How should I myself at this instant know that there exists more than what is now present to me? Why, then, cannot we be mere sceptics, doubting all reality not now and here given?"

I reply at once: State your doubt in a more precise form. Tell what it means. What hypothesis, if any, do you oppose to our own thesis as to this complete and individual, this teleological constitution of the realm of Being, which we have asserted as our Fourth Conception. What is it that you doubt? And what alternative would be true if your doubt were well founded? Hesitate not to give your doubt all possible precision. Philosophy lives upon the comprehension of the meaning of its own doubts.

Let one then say, by way of a mere trial at scepticism: "Beyond a given circle of experience, supposed to be at present known to you and to me, or to me alone, there may be Nothing at all. Let us then suppose, for argument's sake, that there is nothing at all beyond what you or I may just now feel to be present, as our empirical facts, as our passing conscious ideas, desires, hopes, as our so-called memories, and as the problems of the instant. Let that be the realm of Being. Let there be supposed to be naught in the universe but just this. Now this little realm of given fact has no consciously experienced finality about it, no wholeness, no satisfying constitution, no absoluteness. Yet this little realm of passing consciousness somehow exists. How then shall this Fourth Conception of Being refute the purely sceptical hypothesis thus made? And unless such a sceptical hypothesis is refuted, how can any assertions which transcend the instantaneous limits of our human form of consciousness be made in any wise certain?"

So far the doubter's hypothesis. I reply: This doubt, once stated as a possible account of a realm of Being, has all the responsibilities 
of any ontology. It hypothetically defines as real, a supposed, or given, finite circle of empirical facts, called this instant's contents. It supposes this circle to be conceived, for the moment, as the whole of Being, as all that there is. Well, what does this hypothetical assertion mean? Stripped of its accessories, it means simply: A certain finite momentary collection of empirical facts, ideas, desires, etc., merely called the present moment, is the universe. Now, to simplify the matter, name this finite conscious instant of experience, of thought and of will, A. One supposes that A is all, or that nothing but A exists. Well, this assertion, like any other metaphysical one, involves a what and a that. Moreover, it asserts the non-being of anything but A. Now an assertion of non-being is subject to the same general conditions as an assertion of Being. Whatever one means by Being, the meaning of the negative of Being, or of the assertion that something does not exist, is determined by the sense given to the predicate by which one affirms Being. Premising this, then, let one estimate the consistency of the hypothesis now in question.

If one asserts; $A$ is all or, There is naught but $A$, the assertion involves ideas, and if it means anything these ideas possess some object. Now by hypothesis, the present moment, or A, does not itself contain the direct experience of the fact that it includes the whole universe of Being. For if A were certainly aware that nothing besides itself could exist, it would consciously have present what exhausted, even in the very present consciousness of $\mathrm{A}$, the whole possible meaning of the idea of Being. But A would itself then be a completely embodied meaning, an absolutely self-possessed Whole of experience, fulfilling its own purpose. Or in other words, our own Fourth Conception of Being would directly apply to it. And our doubter would then be no mere sceptic; for his positive account would be ours. But since, by hypothesis, A is a passing moment, a dissatisfied instant of finite human experience, the fact that it comprises all that is real is not itself present to the experience of A. And the non-being of all except A, the exclusion from Being of all not present in A, is supposed to be a fact, but a fact whose that, whose very existence as a real fact, must consequently be sought elsewhere than in the conscious experience present to A alone. This already contradicts the hypothesis here in question, as we first stated it. For the fact that A is all Being cannot itself be part of the experience of a consciously fragmentary, or dissatisfied A. Yet A was, 
by hypothesis, to contain all Being. Our sceptic, then, if you suppose him a mere partisan of experience as the only reality, has begun by contradicting himself.

But this is not all. This supposed fact, that $A$ is all Being, or that Naught but $A$ exists, may indeed next be made formally consistent with itself by an amendment. Let the hypothesis now run, as amended thus: "A contains all experience, or all conscious fact, but besides this conscious fact there does exist the unconscious fact, the mere brute reality, unknown to anybody, and present to nobody's experience, the mere fact that $A$ is, not indeed all Being, but all Experience." The sceptical hypothesis thus amended leads, however, at once, to precisely our foregoing alternatives as to the sense in which this supposed fact of the loneliness of A can be asserted as a real fact. That there is no experience in the universe except $A$, is now supposed to be itself a fact, but a fact whose reality nobody experiences. But what kind of Being has this fact? It is, by hypothesis, the object to which the sceptical assertion relates. As such object, other than the sceptic's assertion, but really meant by him as a truth, it is in the position that we have now exhaustively discussed. It cannot be a fact whose Being is wholly independent of the sceptic's own assertion, nor yet a being of the mystical type, nor a merely universal valid truth, of the type of our Third Conception of Being. For all these types of Being have been found logically wanting. Nor can it be in any sense an object merely agreeing with our sceptic's assertion, and externally correspondent thereto. For external agreement with an idea that asserts Being, when such agreement is taken alone, constitutes neither the Being of any object, nor the truth of any idea. That A is the only existent experience must, therefore, be a fact which, as an individual fact, fulfils the will embodied in the sceptic's hypothesis, both in so far as this will refers to that fact, and in so far as the sceptic himself inevitably, even in still supposing the non-being of all but A, talks of Being in general and of the universe in its wholeness. The only possible result is that, in asserting that $\mathrm{A}$ is all experience, the sceptic's hypothesis, if consistent with itself, asserts that A itself consciously contains, presents, and fulfils the whole meaning involved in the idea of Being; or in other words that $\mathrm{A}$ is not a mere passing thrill of human experience, but is an absolute experience, self-determined, self-contained, individual, whole, and therefore final.

The sceptic's hypothesis, therefore, so soon as it is made explicit, 
wholly agrees with our own. Nothing can be but such a whole experience.

\section{$\mathbf{V}$}

But our empirical objector may finally turn upon us with another version of his parable. "Who," he may say, "could for a day attempt to hold your Fourth Conception of Being, and still face a single one of the most characteristic facts of human experience, a single practical failure, a single case where dear hopes have to be resigned, an hour of darkness and private despair, a public calamity, or even a sleepless night,-who I say could face such commonplace facts and not have the observation thrust, as it were, upon him by the seemingly irresistible powers of this world,-the well-known observation: 'You reason in vain: these hard facts are against you.' Your view is too simple for this our complex real world. What is, does not in any essential way fulfil ideas. What is real, is once more whatever experience shows to exist. And experience contains all sorts of nonfulfilments and irrationalities. Chaos or order, joy or defeat, tears of despair and shouts of victory, mysteries, storms, north winds, wars, the wreck of hearts, the might of evil, the meteors that wander in interplanetary darkness, the suns that waste their radiant energy in the chill depths of lifeless space,-these all are facts,-these are Beings. Why talk of Being? What Being in itself is, may well remain unknowable. But what is consistent with the existence of facts, you experience whenever you observe just such wretchedly irrational facts as these. Whatever they mean, they involve not fulfilment, but defeat, of purpose. And that is what you yourself experience whenever you lose what is dear, and face the insoluble mysteries of experience."

The practical weight of such objections can escape no one. They constitute in one aspect the well-known problem of evil. With the positive solution of this problem for its own sake we are not yet directly concerned. That belongs later in these discussions. Our concern at the moment is less with the pathetic than with the purely logical aspect of such objections. What they point out is that, empirically, there are countless, if essentially fragmentary, empirical facts to be recognized, which do not at present come to us human beings as the embodiment of certain specified purposes. These facts appear as involving the temporal defeat of these very purposes in 
just these passing instants of wavering search for Being wherein we now are. We call these facts,-such facts as storms, as war, as defeat and despair, as north winds and sleepless nights,-facts belonging somehow to the realm of Being. Yet they are facts that, when spoken of as ills, are so far defined with reference to the ideas which they just now temporally defeat. How do they stand with reference to our definition of Being?

I reply, for the first, by distinguishing two aspects of any unwelcome facts, such as the empirical observer of human destiny may find to be present in the world. These two aspects are indeed not to be sundered, and are here distinguished only for the sake of present convenience. Yet we shall profit by taking care not blindly to confuse them. Any unwelcome empirical fact has, namely, its own positive characters, as a fact that in our human experience appears at a point of time, in certain relations in space, and with numerous other positively definable features, all of which the thought of any historian or any student of science who describes the fact, may define as the object of his own ideas. In addition to these, its own relatively internal and positive features, the unwelcome fact also appears as involving the present temporal defeat of a purpose which, but for this fact, might here have been won. Now these two aspects of the unwelcome fact were long ago distinguished by the ancient as well as by the mediæval students of the problem of evil. "Every evil," said such students, "has, as a positive fact in the world of Being, its own internal perfections. Its evil character is due to its relations to other facts that coexist with it in the same world. Even Satan," said such views, "is an angel; and even as a fallen angel he has extraordinary perfections of nature, which so far constitute a good. His diabolical quality is due to the misuse of precisely these perfections. The best in wrong setting becomes the worst." Upon such bases these older accounts of evil undertook to make the presence of evil in the world consistent with the well known thesis, Omne Ens est bonum,-a thesis whose historical relation to our own conception of Being I am far from attempting to deny.

Now I indeed have no doubt that these ancient and mediæval students of the problem of evil often made their own task far too light. Nor am I here concerned to accept their special solutions of the problem as to the place of ill in a divinely ordered world. But it does concern us here to point out that an unwelcome fact of human experience has in general these two sorts of characters, 
namely, the characters which make it a positively definable temporal and spatial fact,--so far like any other fact of experience,-and the characters which make us say, that it defeats this or that human purpose.

Thus physical death appears in our experience as an occurrence resulting from a series of physiological processes. As a natural phenomenon its very prevalence is of a deep rational interest. Meanwhile, it involves chemical and physical changes which are not essentially different from countless other changes going on in the organic world. For science it therefore has the same sort of importance that any other event in the biological realm may come to have. On this side, one can say that death is definable as an objective fact rendering relatively true, in their own fragmentary degree, our ideas about death. And this one can say in the same sense as that in which one can make this assertion about any natural fact whatever. If our theory of Being assigns to every objective fact a character as a relative fulfilment of the ideas which refer to it, death also, in so far as it fulfils ideas about death, is to just this extent no instance against our theory. Or, in case you will to know the facts about death, would your will be fulfilled if you remained ignorant of death? Or, once more, as facts now are, for us human beings, would you prefer to remain as innocent of any knowledge of death as much lower animals than ourselves may be ignorant? If you ask a question about death, is your will yet fulfilled in case experience refuses the answer? Would not many amongst us prefer to know much more than we now do as to when and how we ourselves are to die? Is not the very uncertainty of the time of death one of its ills for every prudent man? So much then for one aspect of the empirical ill called death. So far, to know its Being is relatively and imperfectly to fulfil ideas. And our theory defines its Being in terms of this fulfilment.

But death-and, above all, not our own death nearly so much as the death of our friends-is an evil in so far as it appears in our experience as a temporal defeat of the purposes of human love, and of the need of the human world for its good men. Well, this is the other, and, for our own theory, indeed, the more problematic aspect of death. For here the passing fragment of fact is that a given human purpose is so far defeated. And this fragment of fact, as we admit, is obviously somehow a part of the real,-a fact of finite Being. And yet our theory asserts that what is, as such, fulfils purposes, and fulfils too the very purposes of our ideas. 
I have emphasized death as merely one instance, and by no means of course the worst instance, of that inestimably pathetic story of human defeat and misfortune to which our previous examples a moment ago made reference. Now of course I accept to the full the responsibility of our theory to account in the end, not for the mere fact that some finite purposes are defeated, but for the fact that, in human experience, the very purposes which refer, as ideal strivings, to certain objects as their ends, appear, so far as our more direct mortal ken extends, to be for the instant defeated in presence of the very objects to which they have made reference. It is I who fear my friend's death, and hope for his survival. Yet he dies. I have thought beforehand of my object, namely, of my friend's coming destiny. But my object has so far, at least in a measure, entered into my experience, and has overwhelmed me, whose idea defined the object, with the despair of non-fulfilment. Here is a Being in apparently direct conflict with its own idea, and an idea apparently at war with its own object. How is our theory to explain this?

I answer, in the first place, precisely as the mystic would have done in a similar case: By our own definition of Being, you have not empirically found your whole final object, the entire and individual fact of Being that you seek, so long as you seek still for an Other. It is precisely as the Other that Being is not yet empirically present. Loneliness and despair, just because they are dissatisfied, look beyond themselves for Being. And in presence of death you do thus seek for the Other, namely, for the meaning of this fact, for the solution of this mystery, for the beloved object that is gone, for the lost life, for something not here, for the unseen,-yes, for the Eternal. And in this your search for the eternal lies for you the very meaning of death and of finite despair.

As Mary passionately cried, "They have taken away my Lord, and I know not where they have laid him," so every mourner knows precisely this,-that true Being is not finally here where death is, but is elsewhere. The true object, then, the actual Being that you seek, is not found, but merely seems to be lost, at the moment of death. Where, then, is that object? Not here, Not here, cries despair. Aye, Elsewhere, answers our teaching, Elsewhere is precisely the true Being that you seek. Look, then, elsewhere. Seek not the living among the dead.

But you will reply: Have we not just admitted that death itself is, like any other amongst our countless human disasters, a fact of experience? Is not a fact an object? Is not an object real? Have we not 
ourselves called it so? Aye, but we have not said that death is by itself a Whole object. Death, as far as it comes into our experience, is indeed a glimpse of fact, but in the moral world it is the most fragmentary of such glimpses of reality. Whoever faces it faces nothing that he finds as an individual and present reality. What he observes is the absence of precisely what he himself defines as the Whole of Being that he seeks,- the very longing of an unfulfilled idea, which defines the Other, and looks elsewhere for the reality.

Now our theory merely consists in asserting that in every such case the reality sought is a life, and a concrete life of fulfilment, and that this reality is, and is in its wholeness, elsewhere than at this fragmentary instant of human experience. Human experience offers, so far as it goes, only a confirmation of this our view. For we have said that true Being is essentially a Whole Individual Fact, that does not send you beyond itself, and that is, therefore, in its wholeness, deathless. Where death is, Being in its wholeness is not.

"But," so one insists, "but my grief, my defeat, my despair; are they not real? And are they real as determined facts?" I reply: Our theory is indeed responsible for an account of how the temporal and empirical defeat of a specific, although always fragmentary, human purpose can be an incident in a deathless life which in its wholeness involves the fulfilment of a purpose, and of a purpose which includes the very fragmentary purpose now temporally defeated. That account, in its more complete statement, belongs elsewhere, as the explicit discussion of the problem of evil. It is enough at present to point out what all the strongest of human souls have observed and reported as a fact of experience; namely, that through the endurance and the conquest over its own internal ills the spirit wins its best conscious fulfilment. What if this moment of despair be but the beginning, or the fragment, of your whole life as this winning of the object that you now seek? Our theory maintains that, in fact, this is the case. That the fulfilment of the whole of a purpose may involve the defeat of a part of this very purpose, every experience of the beauty of tragedy, of the glory of courage, of the nobility of endurance, of the triumph over our own selves, empirically illustrates.

For tragedy wins our interest by making us suffer, and yet consent to endure, not the tragic hero's suffering, but our own, for the sake of the spiritual beauty that we thereby learn to contemplate. Courage is glorious, because it involves a conquest over our own con- 
scious shrinking in the presence of danger. Who fears not knows not conscious courage. Endurance is noble, because it includes a voluntary defeat of our own unwillingness to endure. And, in general, every form of more complex rational life means a triumph over ourselves whereby alone we win ourselves. Whoever has not faced problems as problems, mysteries as mysteries, defeats as defeats, knows not what that completer possession of his own life means which is the outcome and also the present experience of triumph in the midst of finitude and disaster. For in the victorious warfare with finitude consists the perfection of the spirit. 
